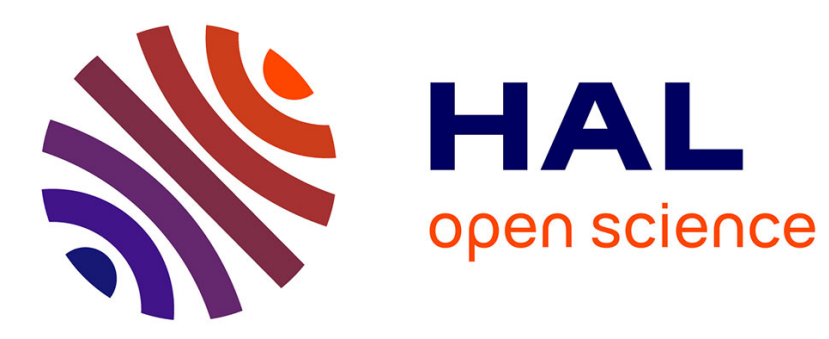

\title{
The Adoption of Smartphones Among Older Adults in China
}

\author{
Shang Gao, Yuhao Yang, John Krogstie
}

\section{To cite this version:}

Shang Gao, Yuhao Yang, John Krogstie. The Adoption of Smartphones Among Older Adults in China. 16th International Conference on Informatics and Semiotics in Organisations (ICISO), Mar 2015, Toulouse, France. pp.112-122, 10.1007/978-3-319-16274-4_12 . hal-01324969

\section{HAL Id: hal-01324969 \\ https://inria.hal.science/hal-01324969}

Submitted on 1 Jun 2016

HAL is a multi-disciplinary open access archive for the deposit and dissemination of scientific research documents, whether they are published or not. The documents may come from teaching and research institutions in France or abroad, or from public or private research centers.
L'archive ouverte pluridisciplinaire HAL, est destinée au dépôt et à la diffusion de documents scientifiques de niveau recherche, publiés ou non, émanant des établissements d'enseignement et de recherche français ou étrangers, des laboratoires publics ou privés.

\section{(c)(1)}

Distributed under a Creative Commons Attribution| 4.0 International License 


\title{
The Adoption of Smartphones Among Older Adults in China
}

\author{
Shang $\mathrm{Gao}^{1}$, Yuhao Yang $^{2}$, John Krogstie ${ }^{1}$ \\ ${ }^{1}$ Department of Computer and Information Science, \\ Norwegian University of Science and Technology \\ ${ }^{2}$ School of Business Administration, \\ Zhongnan University of Economics and Law, Wuhan, China \\ shanggao@idi.ntnu.no, vincentyoodfoxmail.com, \\ krogstiedidi.ntnu.no
}

\begin{abstract}
This research aims to investigate the adoption of smartphones with older adults in China. Based on the literature review from previous research, a research model with eight research hypotheses is developed by extending UTAUT with a consideration of observability and compatibility from IDT, and perceived enjoyment and price value. This research model is empirically examined using survey data from a sample of 121 older adults in China. Five research hypotheses were positively significant supported, while three research hypotheses were rejected in this study. The results suggest that social influence, observability, compatibility, performance expectancy and perceived enjoyment, are important determinants for the use and adoption of smartphones with older adults in China.
\end{abstract}

Keywords: Adoption of smartphones · UTAUT · older adults

\section{Introduction}

Today, smartphones become increasingly important in people's daily life. A smart phone is a mobile phone with more advanced computing capability and connectivity than basic feature phones. It allows users to make video calls, download and transfer files, and use internet-based applications. Smartphones have the potential to enhance the quality of people's life $[5,6]$. For instance, people can get immediate access to information on a variety of topics through their smartphones. People get opportunities for entertainment in the form of games, movies, books through their smartphones. Moreover, smartphones can facilitate communication among family, friends and colleagues via social networking tools, emails, etc.

Most countries in the world are experiencing an increase in the average age of their population. The ageing of the population is one of the major challenges most countries have to face over the next few decades [12]. Older adults face challenges when they are using smartphones. A gap seems to exist in the adoption and use of

adfa, p. 1, 2011.

C Springer-Verlag Berlin Heidelberg 2011 
smartphones by older adults. Some typical issues that impact their use of smartphones are as follows, lack of skills, too expensive phones, security and privacy concerns.

Given all the potential benefits smartphones can bring to the daily life of older adults, there is still an urgent need to examine the means to enable older adults to use smartphones. This research intends to bridge the research gap in the adoption of smartphones among older adults in China. The objective of this research is to examine the adoption and usage of smartphones with older adults in China. We attempt to investigate how various factors impact older adults' intention to use smartphones in China by a research model based on previous technology diffusion theories. The term older adult has been defined in a variety of ways in different articles, which ranges from over 40 to over 75 . The distinction of "older" depends upon the specific context under consideration. Most people over 60 lack the essential skills to perform user survey and computer literacy to use smartphones because their education was interrupted during the Cultural Revolution in China. If we defined the older adult as people over 60 , it would be extremely difficult to collect survey data for this research. Therefore, we defined older adult as people over the age of 45 in this study.

The rest of this paper is organized as follows: Section 2 discusses the theoretical background of this study. The research model and hypotheses are presented in Section 3. The research method and results are described in Section 4. This is followed by a discussion of the findings in Section 5. Section 6 concludes this research.

\section{Background}

\subsection{Benefits of use of smartphones for older adults}

Older adults can benefit from the use of smartphones in a number of ways. Mobile services available on smartphones may help older adults enhance communication with their families and friends, enrich their personal interests, and check various healthcare related information. Further, to address the problems raised by ageing population, many countries started Smart Cities project to fulfill older adults' needs across areas such as housing, social participations health care, and community support services, leisure, to make the city environment more elderly friendly. Smartphones can provide personalized health care, social services for older adults. Although there are many mobile services available on smartphones, many older adults are less aware of those services. This could be a potential reason why older adults do not use smartphones.

\subsection{Digital Divide}

Scholarly research on the digital divide has a long history back to the 1990s. Most researchers in Information Systems in the last two decades focus on Internet penetration through the lens of technology diffusion theory (e.g., TAM [4], IDT [14] , UTAUT [18]). The digital divide refers to the gap between those who do and those who do not have access to new forms of information technology [16]. Research on digital divide often starts by looking at users' access to new technologies. The types of access can be defined as 'physical access' and 'beyond access'. An increasing 
number of researchers suggested to study 'beyond access' with additional attention to social, psychological and cultural background. For example, Van Dijk [16] found a shifted research attention on digital divide from physical access to skills and usage. Along with the popularity of computers and digital technologies, the digital divide in terms of physical access seems to be reduced in most developed countries.

The uneven spread of the mobile applications on smartphones has contributed to the popularity of the concept of the 'digital divide' associated with smartphones. It highlights the emerging social gap between those individuals who use mobile applications on smartphones and those who do not. It is believed that the major gap is based on socio-demographic dimensions (e.g., age, region, income, educational background). To reduce digital inequalities, we must understand the reasons for non-users' resistance to the use of smartphones. Investigating this digital inequality is of help to understand the diffusion of smartphones with different ageing populations.

\subsection{The adoption of smartphones with older adults}

Research work has been carried out by researchers in studying various aspects related to the adoption of smartphones [7]. In [3], Chen, et al. combined TAM and innovation diffusion theory (IDT) to study and explain the adoption of smartphones in logistics. Self-efficacy was a strong predictor of behavioral intention through attitude. Based on a study on the performance of mobile applications, Huang et al. [8] indicated that smartphones could become a suitable substitute of traditional computer. But, the performance of the applications on smartphones is poorly understood.

Although significant effort has been done to explore the adoption of smartphones, the research on the adoption of smartphones with older adults is still in its infancy. The samples used in previous research on the adoption of smartphones are relatively young. Concerning the research on the adoption of new technologies by older adults, most previous research [20] tends to focus on the use intention and adoption of computers and Internet by older adults. Lee et al. [10] examined older computer users' constraints at various age stages. An examination of the current literature reveals that few studies have addressed the use and adoption of smartphones by older adults. Pheeraphuttharangkoon [13] investigated the adoption and use of smartphones with older adults in the UK. However, the sample size with people over 50 years old is quite small in their study.

To our best knowledge, we have not found any studies addressing the adoption of smartphones with older adults in China. The digital divide along the age dimension has become a major concern in China. In developed countries, Internet penetration is saturated and average education level is high, it is easier for users to use smartphones. However, the average education level is lower, especially for older adults in China. According to the annual report 2013 from China Internet Network Information Center, the percentage of smartphone users aged above 45 is significantly lower than the younger generation. Therefore, it is worth to carry out this research to better understand older adults' behavior intention to use smartphones in China. 


\section{Research Model and Hypotheses}

A research model that identifies important factors that impact older adults' intention to use smartphones was developed in this research. The proposed research model (see Figure 1) is an extension of UTAUT [18], with a consideration of observability and compatibility from IDT [14], and perceived enjoyment [15] [17] and price value [19] from other technology diffusion theories. We have developed eight research hypotheses based on the research model. Each hypothesis as labeled in Figure 1 is elaborated below.

\section{Hypotheses developed from UTAUT}

Four key factors from UTAUT, Social Influence, Facilitating Conditions, Performance Expectancy and Effort Expectancy, were included in our research model. Social Influence is the extent to which consumers perceive that important others (e.g., family and friends) believe they should use a particular technology. Previous research also indicated that social influence is important for the adoption of smartphones [21]. Facilitating Conditions refer to consumers' perceptions of the resources and support available to perform a behavior. Users need to have digital skills to use smartphones. Performance Expectancy is defined as the degree to which using a technology will provide benefits to consumers in performing certain activities. Smartphones are able to provide potential benefits (e.g., always connected, healthcare information) for users. Once users have recognized these benefits, they are likely to use and adopt smartphones. Effort Expectancy is the degree of ease associated with consumers' use of technology. Learning a new technology often takes time and effort, particularly with older adults. If using smartphones is considered as an easy and straightforward process, users are likely to adopt smartphones. Thus, we proposed the following four hypotheses.

H1: Social Influence (SI) has a positive influence on older adults' intention to use smartphones.

H2: Facilitating Conditions (FC) has a positive influence on older adults' intention to use smartphones.

H3: Performance Expectancy (PE) has a positive influence on older adults' intention to use smartphones.

H4: Effort Expectancy (EE) has a positive influence on older adults' intention to use smartphones.

\section{Hypotheses developed from IDT}

Rogers [14] indicated that innovation that are perceived by individuals as having greater relative advantage, compatibility, trialability, and observability, and less complexity will be adopted more rapidly than other innovation. To further understand older adults' intention to use smartphones, two factors from IDT were included into our research model. As for the case of smartphones, Observability can be defined as the degree to which smartphones are visible to potential users. Compatibility can be seen as users' belief in the consistency of using smartphones with the way they live and work. Previous research also demonstrated that the importance of Observability and Compatibility to the adoption of new technologies (e.g., e-banking [9]). Therefore, the following two hypotheses were proposed.

H5: Observability (OBS) has a positive influence on older adults' intention to use smartphones. 
H6: Compatibility (COM) has a positive influence on older adults' intention to use smartphones.

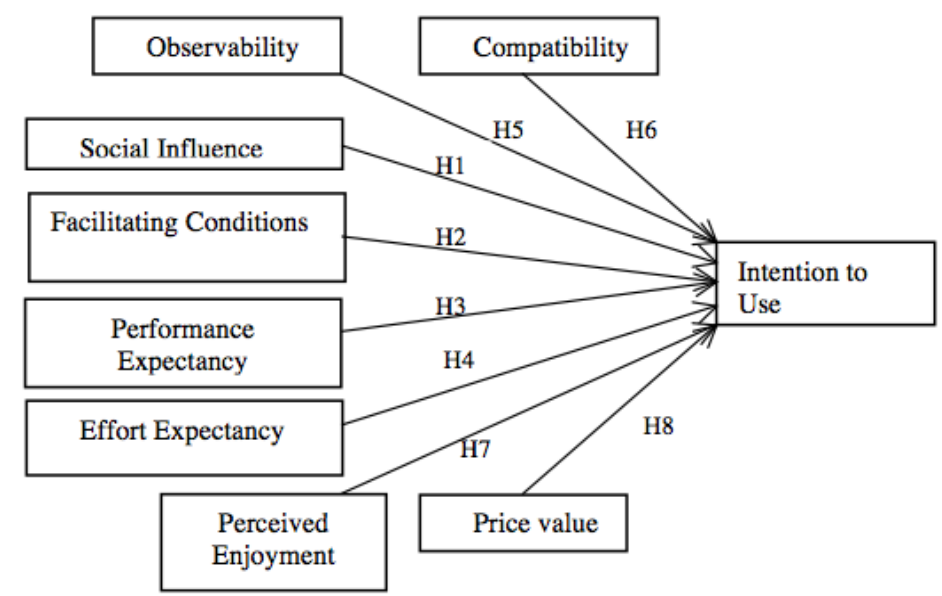

Fig. 1. Research Model

\section{Perceived Enjoyment and Price Value}

Perceived Enjoyment is defined as the extent to which the activity of using a specific system is perceived to be enjoyable in its own right, aside from any performance consequences resulting from system use [15] [17]. Users can have fun when they are playing games, and playing music on smartphones.

Price value is another significant factor affects users' adoption of a new technology. Price value can be defined as consumers' cognitive tradeoff between the perceived benefit of the applications and the monetary cost for using them [19]. It is believed that users are likely to adopt smartphones when the benefits of using smartphones are perceived to be greater than the monetary cost of smartphones. Hence, we proposed the following hypotheses.

H7: Perceived Enjoyment (PEJ) has a positive influence on older adults' intention to use smartphones.

H8: Price Value (PV) has a positive influence on older adults' intention to use smartphones.

\section{An Empirical Study with the Research Model}

To understand older adults' use and adoption of smartphones in China, the proposed research model and hypotheses were empirically tested using the structural equation modeling approach.

\subsection{Instrument Development}

The validated instrument measures from previous research were used as the foundation to create the instrument for this study. In order to ensure that the instrument better fit this empirical study, some minor words changes were made to ensure easy interpretation and comprehension of the questions. For instance, wording was modified 
to fit the context of use of smartphones in China. A questionnaire was developed first in English and then translated into Chinese. Back-translation was conducted by bilingual third party to improve the translation accuracy. As a result, the measurement questionnaire consisted of 25 items $^{1}$. A seven point Likert scale was used to examine participants' responses to all items in this part.

\subsection{Samples}

The data for this study were collected through self-administered questionnaires in the central part of China. The survey was distributed in terms of paper-based questionnaires individually from Aug 20th 2014 to Sep 30th, 2014. 132 completed questionnaires were collected, among which 121 of them were valid questionnaires (i.e., valid respondent rate $91.7 \%$ ). Among the participants, 72 of the participants were male, and 49 were female. Moreover, $79.3 \%$ of participants had full-time jobs, $10.8 \%$ of participates had part-time jobs, $9.8 \%$ of participants had retired. Further, the top three most used featured on smartphones for the participants were: making phone calls, text messaging, and instant messaging feature (e.g., QQ, Wechat).

Table 1. Factor loadings, composite reliability, and AVE for each construct

\begin{tabular}{|c|c|c|c|c|c|c|}
\hline Construct & Item & $\begin{array}{l}\text { Factor } \\
\text { ing }\end{array}$ & Load- & $\begin{array}{l}\text { Composite } \\
\text { Reliability }\end{array}$ & AVE & $\begin{array}{l}\text { Cronbach's } \\
\text { Alpha }\end{array}$ \\
\hline \multirow[t]{3}{*}{$\overline{\mathrm{SI}}$} & SI1 & 0.835 & & 0.91 & 0.77 & 0.85 \\
\hline & SI2 & 0.947 & & & & \\
\hline & SI3 & 0.840 & & & & \\
\hline \multirow[t]{4}{*}{$\mathrm{FC}$} & $\mathrm{FC} 1$ & 0.864 & & 0.91 & 0.71 & 0.87 \\
\hline & $\mathrm{FC} 2$ & 0.790 & & & & \\
\hline & $\mathrm{FC} 4$ & 0.887 & & & & \\
\hline & FC4 & 0.835 & & & & \\
\hline \multirow[t]{3}{*}{$\mathrm{PE}$} & PE1 & 0.860 & & 0.90 & 0.75 & 0.83 \\
\hline & PE2 & 0.929 & & & & \\
\hline & PE3 & 0.804 & & & & \\
\hline \multirow[t]{3}{*}{$\mathrm{EE}$} & EE1 & 0.941 & & 0.95 & 0.87 & 0.93 \\
\hline & EE2 & 0.941 & & & & \\
\hline & EE3 & 0.917 & & & & \\
\hline \multirow[t]{2}{*}{ OBS } & OBS1 & 0.939 & & 0.94 & 0.89 & 0.87 \\
\hline & OBS2 & 0.946 & & & & \\
\hline \multirow[t]{3}{*}{$\mathrm{COM}$} & COM1 & 0.941 & & 0.95 & 0.87 & 0.92 \\
\hline & COM2 & 0.948 & & & & \\
\hline & COM3 & 0.905 & & & & \\
\hline \multirow[t]{2}{*}{ PEJ } & PEJ1 & 0.937 & & 0.94 & 0.89 & 0.87 \\
\hline & PEJ2 & 0.947 & & & & \\
\hline \multirow[t]{3}{*}{ PV } & PV1 & 0.827 & & 0.93 & 0.82 & 0.89 \\
\hline & PV2 & 0.945 & & & & \\
\hline & PV3 & 0.936 & & & & \\
\hline \multirow[t]{2}{*}{$\mathrm{IU}$} & IU1 & 0.952 & & 0.95 & 0.91 & 0.91 \\
\hline & IU2 & 0.960 & & & & \\
\hline
\end{tabular}

\footnotetext{
${ }^{1}$ The survey items are available at this link: http://www.idi.ntnu.no/ shanggao/oldadults.html
} 


\subsection{Measurement Model}

The quality of the measurement model is determined by (1). Content validity, (2). Construct reliability and (3). Discriminant validity [1]. To ensure the content validity of our constructs, a pre-test of the questionnaire with a small group of respondents was conducted before the survey was distributed. To further test the reliability and validity of each construct in the research model, the Internal Consistency of Reliability (ICR) of each construct was tested with Cronbach's Alpha coefficient. As a result, the Cronbach's Alpha values range from 0.83 to 0.93 . A score of 0.7 is marked as an acceptable reliability coefficient for Cronbach's Alpha. All the constructs were above 0.70 .

Convergent validity was assessed through composite reliability (CR) and the average variance extracted (AVE). Bagozzi and Yi [2] proposed the following three measurement criteria: factor loadings for all items should exceed 0.5, the CR should exceed 0.7 , and the AVE of each construct should exceed 0.5. As shown in Table 1, all constructs were in acceptable ranges.

The measurements of discriminant validity were presented in Table 2. According to the results, the variances extracted by the constructs were more than the squared correlations among variables. The fact revealed that constructs were empirically distinct. As good results for convergent validity and discriminant validity were achieved, the test result of the measurement model was good.

Table 2. Discriminant Validity

\begin{tabular}{llllllllll}
\hline Variables & SI & FC & PE & EE & Obs & Com & PEJ & PV & IU \\
\hline SI & $\mathbf{0 . 8 8}$ & & & & & & & & \\
FC & 0.66 & $\mathbf{0 . 8 4}$ & & & & & & & \\
PE & 0.51 & 0.47 & $\mathbf{0 . 8 7}$ & & & & & & \\
EE & 0.43 & 0.43 & 0.38 & $\mathbf{0 . 9 3}$ & & & & & \\
Obs & 0.19 & 0.29 & 0.15 & 0.28 & $\mathbf{0 . 9 4}$ & & & & \\
Com & 0.73 & 0.52 & 0.59 & 0.50 & 0.15 & $\mathbf{0 . 9 3}$ & & & \\
PEJ & 0.60 & 0.47 & 0.49 & 0.46 & 0.37 & 0.63 & $\mathbf{0 . 9 4}$ & & \\
PV & 0.57 & 0.37 & 0.34 & 0.33 & 0.17 & 0.44 & 0.47 & $\mathbf{0 . 9 0}$ & \\
IU & 0.64 & 0.52 & 0.60 & 0.41 & 0.42 & 0.69 & 0.82 & 0.42 & $\mathbf{0 . 9 6}$ \\
\hline
\end{tabular}

Note: Diagonals represent the average variance extracted, while the other matrix entries represent the squared correlations.

\subsection{Structural Model and Hypotheses Testing}

The structural model was tested using Amos 20.0. The results of the structural model are shown in Figure 2. The $\mathrm{R}^{2}$ ( $\mathrm{R}$ square) in Figure 2 denotes to coefficient of determination. It provides a measure of how well future outcomes are likely to be predicted by the model, the amount of variability of a given construct. In our analysis, the $\mathrm{R}^{2}$ coefficient of determination is a statistical measure of how well the regression coefficients approximate the real data point. According to the result, $77 \%$ of the variance of behavior intention can be explained by the research model. 
The standardized path coefficients between constructs are presented, while the dotted lines stand for the non-significant paths. Table 3 presents the path coefficients, which are standardized regression coefficients. As a result, five (H1, H3, H5, H6, H7) of the proposed eight hypotheses were supported. The positive effects of perceived enjoyment on intention to use was quite strong, as indicated by the path coefficient of 0.85 $(p<0.05)$. The other path coefficients of compatibility, observability, social influence, and performance expectation, to intention to use were statistically positively significant at $\mathrm{p}<0.05$. But, there was no significant positive impact of facilitating conditions, effort expectancy, and price value on the intention to use smartphones with older adults. Therefore, $\mathrm{H} 2, \mathrm{H} 4$, and $\mathrm{H} 8$ were rejected.

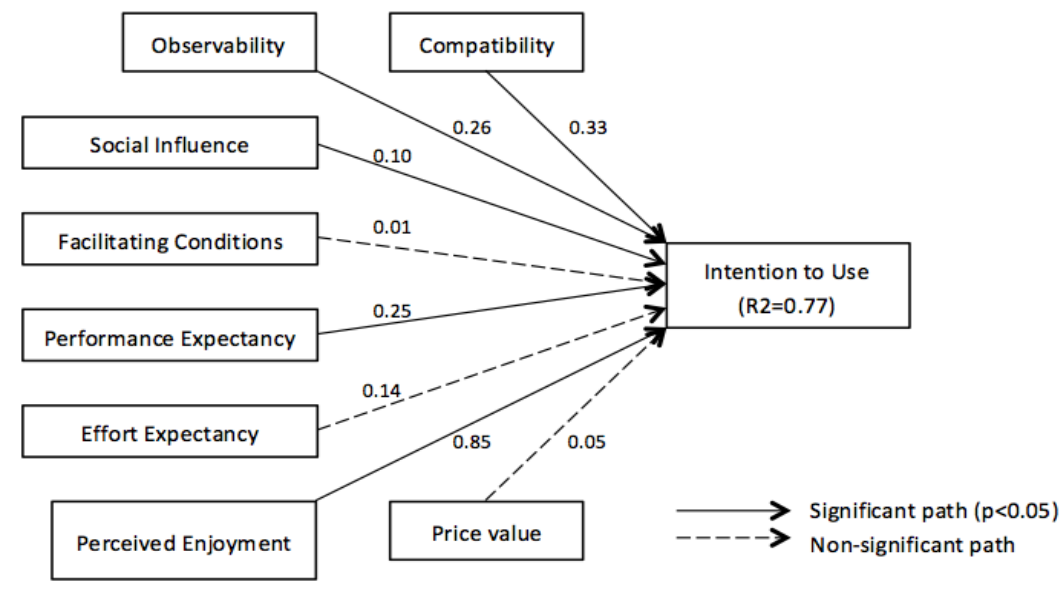

Fig. 2. Results of structural modeling analysis

Table 3. Test of hypotheses based on path coefficient

\begin{tabular}{lll}
\hline Hypothesis & $\begin{array}{l}\text { Path } \\
\text { Coefficient }\end{array}$ & Hypothesis \\
& Result \\
\hline H1 & $0.10^{*}$ & Supported \\
H2 & 0.01 & Rejected \\
H3 & $0.25 * * *$ & Supported \\
H4 & -0.14 & Rejected \\
H5 & $0.26^{* * *}$ & Supported \\
H6 & $0.33^{* * *}$ & Supported \\
H7 & $0.85^{* * *}$ & Supported \\
H8 & -0.05 & Rejected \\
\hline
\end{tabular}

\section{Discussion}

In this research, we studied the adoption of smartphones with older adults in China. The most important determinant for users' intention to use smartphones was perceived enjoyment. If using smartphones is fun, older adults are more likely to accept 
smartphones. Further, social influence was proved to be important for the use and adoption of smartphones with older adults. It means that the opinions of friends and family have a positive impact on older adults' intention to use smartphones.

Performance expectancy had a significant positive impact on older adults' intention to use smartphones, while effort expectancy did not have a strong positive influence on older adults' intention to use smartphones. It seemed that older adults did not use smartphones just because it was easy to use, but rather because they found it useful for their work and life. Therefore, smartphones providers need to develop better solutions to make smartphones more useful. This also implied that content providers of apps on smartphones have to pay more attention to the usefulness of the content available on smartphones for older adults.

There was no significant positive impact of facilitating conditions on the intention to use smartphones with older adults. One possible reason was that facilitating conditions might be considered as a limiting factor when the needed facilitating conditions are not perceived by older adults. Therefore, the presence of the facilitating conditions did not motivate older adults to use smartphones. Another interesting finding was that price value had no significant positive impact on the intention to use smartphones with older adults. Since smartphones become inexpensive (e.g., the cheapest model from MI costs 100 USD) in China, most participants in this study can afford smartphones. It seems that they tend to focus on the factor (e.g., perceived enjoyments, performance expectancy) when using smartphones. Therefore, price value of smartphones becomes unimportant when it comes to the adoption of smartphones with older adults in China.

However, we were also aware of some limitations. Firstly, we only tested the research model and research hypotheses with older adults from five provinces in the central part of China. This sample might not be fully representative of the entire older adults in China. Secondly, all the data were collected using self-reported scales in the research. This may lead to some caution because common method variance may account for some of the results that has been cited as one of the stronger criticisms of tests of theories with TAM and TAM-extended research [11]. However, our data analysis with convergent and discriminant validity does not support the presence of a strong common methods factor. Last but not least, the findings of this study may be limited due to the relatively small sample size.

\section{Conclusion and Future Research}

This research was designed to study the adoption of smartphones with older adults in China. To the best of our knowledge, we have not found any studies concerned with older adults' intention to use smartphones in China. This study investigated older adults' adoption of smartphones by extending UTAUT with a consideration of observability and compatibility from IDT, and perceived enjoyment and price value. A research model with eight research hypotheses was proposed in the study. Five research hypotheses were positively significantly supported, while three research hypotheses were rejected in this study. 
Continuing with this stream of research, we plan to further examine the applicability of the research model with other group of users in China (e.g., people below 45 years old). Future research is also needed to empirically verify the research model with larger samples across the world. We also plan to carry out a comparative study with older adults in the developed countries.

\section{References}

1. Bagozzi, R.P.: The role of measurement in theory construction and hypothesis testing: toward a holistic model. In: Ferrell, O.C., Brown, S.W. and Lamb, C.W. (eds.) Conceptual and theoretical developments in marketing, 15-32 (1979)

2. Bagozzi, R.P. and Yi, Y.: Specification, evaluation, and interpretation of structural equation models. Journal of the Academy of Marketing Science. 40 (1), 8-34 (2012)

3. Chen, J.V., Yen, D.C. and Chen, K.: The acceptance and diffusion of the innovative smart phone use: A case study of a delivery service company in logistics. Information \& Management. 46 (4), 241-248 (2009)

4. Davis, F.D.: Perceived usefulness, perceived ease of use and user acceptance of information technology. MIS Quarterly. 13 (3), 319-340 (1989)

5. Gao, S., Krogstie, J., Chen, Z., et al.: Lifestyles and Mobile Services Adoption in China. International Journal of E-Business Research (IJEBR). 10 (3), 36-53 (2014)

6. Gao, S., Krogstie, J. and Siau, K.: Adoption of mobile information services: An empirical study. Mobile Information Systems. 10 (2), 147-171 (2014)

7. Gao, S., Krogstie, J. and Siau, K.: Developing an Instrument to Measure the Adoption of Mobile Services. Mobile Information Systems. 7 (1), 45-67 (2011)

8. Huang, J., Xu, Q., Tiwana, B., et al.: Anatomizing application performance differences on smartphones. In: Proceedings of the 8th international conference on Mobile systems, applications, and services, 165-178. ACM (2010)

9. Kolodinsky, J.M., Hogarth, J.M. and Hilgert, M.A.: The adoption of electronic banking technologies by US consumers. International Journal of Bank Marketing. 22 (4), 238-259 (2004)

10. Lee, B., Chen, Y. and Hewitt, L.: Age differences in constraints encountered by seniors in their use of computers and the internet. Computers in Human Behavior. 27 (3), 1231-1237 (2011)

11. Malhotra, N.K., Kim, S.S. and Patil, A.: Common method variance in IS research: A comparison of alternative approaches and a reanalysis of past research. Management Science. 52 (12), 1865-1883 (2006)

12. Peacock, S.E. and Künemund, H.: Senior citizens and Internet technology. European journal of ageing. 4 (4), 191-200 (2007)

13. Pheeraphuttharangkoon, S., Choudrie, J., Zamani, E., et al.: Investigating the adoption and use of smartphones in the UK: a silver-surfers perspective. In: the 22nd European Conference on Information Systems (ECIS2014) (2014)

14. Rogers, E.M.: The diffusion of innovations. Free Press, New York (1995)

15. Van der Heijden, H.: Factors influencing the usage of websites: the case of a generic portal in The Netherlands. Information \& Management. 40 (6), 541-549 (2003)

16. Van Dijk, J.A.: Digital divide research, achievements and shortcomings. Poetics. 34 (4), 221-235 (2006)

17. Venkatesh, V. and Bala, H.: TAM 3: Advancing the technology acceptance model with a focus on interventions. Manuscript in preparation. Retrieved from http://www.vvenkatesh.com/IT/organizations/Theoretical_Models.asp (2013) 
18. Venkatesh, V., Morris, M.G., Davis, G.B., et al.: User Acceptance of Information Technology: Toward a Unified View. MIS Quarterly. 27 (3), 425-478 (2003)

19. Venkatesh, V., Thong, J.Y. and Xu, X.: Consumer acceptance and use of information technology: extending the unified theory of acceptance and use of technology. MIS quarterly. 36 (1), 157-178 (2012)

20. Wagner, N., Hassanein, K. and Head, M.: Computer use by older adults: A multidisciplinary review. Computers in Human Behavior. 26 (5), 870-882 (2010)

21. Zhou, T., Li, H. and Liu, Y.: The effect of flow experience on mobile SNS users' loyalty. Industrial Management \& Data Systems. 110 (6), 930-946 (2010) 